Heads of alternative provision: committed to realising young peoples' potential in an unregulated market

Andrew Malcolm

Applied Social Studies, University of Bedfordshire, Luton, UK

andrew.malcolm@beds.ac.uk

ODCID ID: orcid.org/0000-0002-8137-8122 


\section{Heads of alternative provision: committed to realising young peoples' potential in an unregulated market}

Alternative provision caters for pupils who are marginalised and excluded from mainstream schooling. In England it is generally conceptualised in policy terms as providing education to support behavioural improvements (pupils are directed off site to improve behaviour). There is very limited research on the experiences of those who work in alternative provision settings. That which does exist tends to report the commitment of these professionals to the young people with whom they work. Young people who attend these schools almost without fail talk about the relationships they experience there and the positive impact they have on them. As such there is a need to better understand the choices and motivations of those working with these young people if we are to understand the key relationships that make alternative provision work. This article fills a gap by focusing on the experiences of those managing AP settings across a geographical area and was undertaken as part of the author's professional doctorate. The findings are based on three interviews and 20 surveys and develop significantly our understanding of the motivations of those working in and managing alternative provision settings. Interesting divergences in practice are highlighted across settings and evidence is presented which shows that managers both see and work to realise the potential of the young people who attend alternative provision. Indeed, these findings suggest staff commitment should be conceptualised as belief in the potential of the young people who attend alternative provision. Keywords: alternative provision; staff; exclusion; heads 


\section{Introduction}

Given the extent to which young people refer to the positive relationships they experience in alternative provision (AP) there is need to better understand the role staff play in this. This paper explores the motivations and experiences of heads of AP settings across one English county. This paper offers a viewpoint which sits somewhere between the work of Farouk (2014) who focused on the experiences of three teachers when moving into an AP setting; and Thomson and Pennacchia (2014) who undertook a review of quality alternative provision across the UK and include a discussion of staff perspectives. The value of this research is that the voices of heads of provision from a single geographical location are bought together. This enables consideration of similarities and divergences in practice across AP settings delivering part and full time and short and long term placements, and a range of educational opportunities from single focus to full National Curriculum provision. This significantly develops our understanding of the motivations and expectations of those working in and managing AP. The findings are likely to have relevance when considering the variety of alternative provision available in England. Indeed, this research is open to even broader application given that over time and place there is 'remarkable congruence ... in the research on what are understood as the 'best practices' of alternative education' (Thomson, 2014, 20).

Alternative provision is defined in England as timetabled educational activities away from the school site and school staff (Taylor, 2012) and can be part or full time, short or long term. Settings include pupil referral units (PRUs), AP academies (PRUs which have converted to academy status) and AP free schools (newly opened AP in receipt of central government support) as well as a wide range of alternative provision run by independent organisations such as charities and private companies, some of which will have independent school status. Research and reports refer to an extremely wide variety of subjects and teaching approaches 
available in AP (Thomson and Russell, 2009; Ofsted, 2011; and Kendall et al., 2003).

Although all three of these sources provide analysis of the types of provision available the work of Thomson and Russell is most developed in categorising AP programmes as either work-related, focusing on basic/life skills, recreation based, therapeutic or academic (2009). Providers can, and frequently do, provide more than one of these types of programme.

\section{Views on provision - a review of the literature}

The existing research relating to alternative provision tends to either focus on the young people who attend or on reviewing the provision available ${ }^{1}$. Research on young people's experiences of alternative provision has consistently found that relationships are key. This has been described as 'feeling respected as individuals and learners' (Pomeroy, 1999, 479), being treated 'more like an adult' (McCluskey et al., 2015, 601), the importance of someone who 'held their story' (Pirrie et al, 2011, 17), young peoples' use of 'familial descriptors' (O Gorman et al., 2015, 7) and relationships as 'fundamental to the practice' experienced in alternative provision (Malcolm, 2015, 123). Other key themes include the importance of staff taking time to listen (Pomeroy, 1999; O Gorman et al., 2015; McCluskey et al., 2015; Malcolm, 2015; Nicholson and Putwain, 2015), the flexibility of both structure and curriculum (O Gorman et al., 2015; Trotman et al., 2015; Malcolm 2015; Nicholson and Putwain, 2015) and a disposition of care (O Gorman et al., 2015; Malcolm 2015; CajicSeigneur and Hodgson, 2016; Solomon and Thomas, 2013; Nicholson and Putwain, 2015). Given the extent to which young people refer to the positive relationships they experience in

\footnotetext{
${ }^{1}$ Reviews tend to either focus on particular programmes or models of provision (Cullen and Monroe, 2010; Cook, 2005; Cajic-Seigneur and Hodgson, 2016) or establishing the extent and structure of AP available across a geographical area (Thomson and Russell, 2009; McCluskey et al., 2013; Ofsted, 2016b; Thomson and Pennacchia, 2014).
} 
AP there is need to better understand the role staff play in this, in particular their initial and on-going motivations for working in this sector. Indeed understanding staff-student relationships is absolutely key to identifying the effectiveness of AP. Developing this understanding is a matter of urgency if Thomson and Pennacchia (2015) are correct in their assertion that behavioural approaches may be in the ascendancy in alternative provision settings despite the relational focus consistently advocated within AP literature.

Research of staff practice in alternative provision settings is related to the experiences reported by students in AP of positive staff-student relationships, staff taking time to listen, there being flexibility of structure and curriculum and of staff exhibiting a disposition of care. There is only limited research which directly considers the experiences of those working in alternative provision (Farrell et al., 2017; Morgan et al., 2015; Farouk, 2014; and Meo and Parker, 2004). With the exception of Morgan et al. who studied a network of five schools in Australia all the articles just cited are case studies in individual schools. While there is some additional evidence in other publications (Garner, 1996; Grundy and Blandford, 1999; Trotman et al., 2015; Woodley, 2016; and Dray, 2017) there is certainly a gap for a broader review of the experiences of those working in and managing AP settings which this article will address. Perhaps there is limited research from staff perspectives because of recommendations that 'research continues to centralise student voice in the area of early school leaving' (O Gorman et al., 2015, 13). However given the value young people place on the relational nature of the provision they receive consideration of the experiences of those working in AP settings should be a priority. The following will review the findings of existing research which explores staff perspectives. 
The key theme which emerges from the existing research on the experiences of staff in AP settings is their commitment to their students. This is variously described as a 'moral commitment' to normalising and responsibilising students (Farrell et al., 2017, 356), a 'collective commitment' to the welfare of students (Meo and Parker, 2004, 107), 'considerable commitment' to work to change things in the lives of young people (Garner, 1996, 194), or a 'shared sense of purpose and drive' (Grundy and Blandford, 1999, 7). It is clear that staff working in alternative provision settings are committed to the students in their care and motivated by a sense of purpose aimed at supporting these young people. The responses of the teachers interviewed by Farouk (2014) also reflect this theme. They chose to work in a PRU because it offered a clearer purpose - the hope to be able to rescue pupils and return them to mainstream. However they discovered far more complexity than this and after becoming involved in the difficult and traumatic experiences of individual pupils at the beginning of their careers in the PRU they learnt a disposition of managed engagement:

teachers need to manage and control their personal engagement with students so that they are able to form constructive learning relationships without also becoming enmeshed in difficulties which they are then unable to resolve (Farouk, 2014, p27)

The need to maintain appropriate emotional distance is also discussed by Woodley (2016). Morgan et al. (2015) undertook research with educators in alternative 'flexi' schools in Australia and found two key ways in which staff conceptualised their roles; relationships and re-engagement. Part of their research design was to undertake reflective practice groups with staff to support their development as 'reflective practitioners' (Morgan et al., 2015, 5). Reflection is an important practice which facilitates positive staff engagement with their students so as to be aware of their own needs and desires and how these interact with their 
experiences of working in challenging situations. This can be particularly important in an environment where 'students will reject the efforts that you have made for them on a regular basis' (Farouk. 2014, 27). Other notable themes in the existing literature include the use of humour (Trotman et al., 2015) or banter (Dray, 2017) and the way in which staff conceptualise what they do against mainstream approaches to schooling (Farouk, 2014 and Garner, 1996).

\section{Unregistered schools and alternative provision}

The recent focus in England on unregistered schools by Ofsted and the DfE (Ofsted, 2016a) is important as it has the potential to shape the nature of AP available in England. Official registration is required for:

any school at which full time education is provided for five or more pupils of compulsory school age, or one or more such pupils with an EHC plan or a statement of special educational needs or who is "looked after" by the local authority (DfE, 2016a, 5).

There is a certain amount of room for interpretation around this definition given the use of the term 'full time' and the frequency with which alternative provision is a part of a young person's schooling rather than its whole. It is arguable that some form of registration of alternative provision schools would be positive ${ }^{2}$. However this would need to be agreed nationally and in the interim it may well be the case that alternative provision settings are impacted by this focus on unregistered schools.

\footnotetext{
${ }^{2}$ For discussion on this topic see Thomson and Pennacchia (2014) who recommend a kite mark system for some providers in conjunction with registration as a school for others where appropriate.
} 


\section{The local authority role vis-à-vis alternative provision}

Though the Educational Excellence Everywhere White Paper (DfE, 2016b) has now been withdrawn the direction of travel set out for AP has been building for a number of years with the school exclusion trial (DfE, 2014) and in all probability will be integrated back into any new education White Paper and subsequent bill. The foundational change is a move from local authorities being responsible for permanently excluded pupils to the excluding school retaining this responsibility unless the pupil is enrolled into another mainstream school. The published notes for the Queen's speech 2016 refer to:

making schools responsible for finding the right provider for their excluded pupils, and accountable for their education (gov.uk, 2016, 35).

This significant shift in the location of responsibility will change the dynamics which shape the alternative provision available in any area and may go some way towards minimising the powerful sorting which marginalises low performing pupils from mainstream into alternative provision settings (Feltcher, Strand, and Thomas 2015, 19).

\section{Methods}

This article is based on survey responses from heads of alternative provision settings [N=20] which receive pupils from across one English county. Survey responses are supplemented with data from interviews $[\mathrm{N}=3$, across two centres $]$ in which the survey was trialled. This research was undertaken in 2013 as part of a professional doctorate investigating the nature of alternative provision and its impact on those who attend. In-line with the nature of a professional doctorate the researcher had worked at one provision and was on the management committee of another in the local area. Interviewees were selected to trial the 
survey where there was a pre-existing relationship with the researcher. This approach allowed for the perspectives of these heads to be included in the research while minimising the extent to which pre-existing relationships introduced bias to the findings. These trials used cognitive interviewing which drew on thinking aloud and verbal probing techniques (Willis, 1999) and was used to delve into the respondents' understanding of individual questions and sections. This was a valuable process for refining the survey and led to the introduction of a number of important questions. The sample selection for the survey was a census of all heads of provision serving the county. There was no definitive list of all the alternative provision programmes available and snowballing had to be used to develop a full list of contacts, Thomson and Russell (2009) note similar difficulties. The response rate for this census survey was 20 out of a possible 28 returns. The ethical considerations for this project largely related to the researchers previous and on-going involvement in the local AP sector ${ }^{3}$. The key risk here was bias and the potential to present preconceived ideas about alternative provision and good practice. Reflection, with supervision, was fundamental to minimising this risk and the findings presented here are firmly grounded in both empirical data and the existing research. Ethical approval for this research was given by a university ethics committee and simple statistical and thematic analysis was undertaken to generate the topics addressed within the findings section.

Of the 20 survey respondents thirteen were female and fourteen had worked in alternative provision for over five years. Seven heads had been in place for over five years, five for between three and five years, six for between one and three years and two had been in place for less than six months. Three quarters of the alternative provision settings in which the respondents worked had been running for over three years, five of these for over ten years.

\footnotetext{
${ }^{3}$ For a full discussion of the ethical issues raised by this doctoral research project see Malcolm (2015).
} 
The heads' responses will be shaped by the particularities of the local area and the organisations they lead. As such, these views and experiences are not simply generalizable to alternative provision across the country. Instead careful argument and evidencing of the wider relevance of the findings must be undertaken to establish their significance for alternative provision more generally. The value of these responses is that they bring together a wide range of models of alternative provision. This makes it possible to consider whether there are underlying similarities and areas of divergence in practice and reflect on what this might mean for the use and practice of alternative provision schooling both within England and beyond.

\section{Findings}

In line with the research reviewed above all provision was on a small scale with most learning occurring in groups of around six students with two staff members and a strong focus on one to one teaching. All respondents considered flexibility and or a supportive, caring environment to be fundamental to their offer. This was aptly summed up by one head who compared their offer to mainstream schooling as:

An alternative and non-judgemental environment. Mainstream education has particular rules and standards, which do not suit all young people. We offer a safe place for the young people to test boundaries in ways mainstream education does not allow (Head of Provision - survey)

The findings will be structured by first considering the models of provision on offer in the county in which this research took place. This will be followed by a fuller discussion of the 
initial and on-going motivations of the heads of provision and of areas of divergence in the practice reported by heads of provision.

\section{The provision available and characteristics of practice}

Within the county in which this research took place, heads of alternative provision who participated in this research used a wide range of models including, an AP free school, independent schools, a PRU, an AP academy, and private limited companies some of which were not for profit and others social enterprises. Other than the AP academy, AP free school and PRU only two providers had obtained status as independent schools. As such 16 out of the 22 providers involved in the research could be significantly impacted by Ofsted's focus on unregistered schools as outlined above. This suggests serious impetus needs to be given to an appropriate system of registration and accountability for AP settings for which full registration as a school is not necessarily appropriate (see note 2 above).

Responses to this survey were used to categorise AP by their primary educational focus. The most common focus was on providing a school offer largely in line with Thomson and Russell's academic category (2009). Seven of the twenty survey respondents had this as their primary focus, all offered GCSE qualifications apart from one where ASDAN qualifications were on offer, this provider would perhaps better fit with Thomson and Russell's basic skills category (2009). Of the other thirteen four focused primarily on arts, and three each on activities, work-related and therapeutic education. These findings would seem at odds with Thomson and Russell (2009) who categorised a total of 172 programmes offered by 150 providers identified across two local authorities. Fewer than one in twenty of the programmes on offer were considered to be academic whereas in this research seven out of the twenty respondent's primary focus was a school offer. This either suggests that provision on offer in 
any local area can vary quite considerably or that over recent years provision has become increasingly academically focused. Variation of provision on offer is in line with the Taylor report on alternative provision which suggests that 'the existence of good quality AP in any one area is usually more a matter of luck than of any systematic planning by schools, PRUs or LAs' (Taylor, 2012, 5). An increasingly academic focus is harder to find evidence for in the existing research but Thomson and Pennacchia (2015) do suggest a rise in the use of behavioural approaches and the findings of Ofsted reports have shown a steady increase in their assessment of the overall quality of provision in England (Dean, 2016). Taken together these may suggest alternative provision settings have increased their academic focus over recent years.

\section{The motivations of heads}

When questioned about their initial and on-going motivation for working in alternative provision heads' reported that perceptions of mainstream schooling as ineffective and unhelpful for some students were often part of their initial motivation. They also discussed the sense of purpose they experienced and the impact they perceived as what kept them there. These themes are in-line with the existing research set out above. One theme emerged which has not been explored to any extent in the existing literature - market dynamics, particularly in relation to initial motivation. These themes will now be considered in greater detail.

Respondents were asked an open question about the key issues facing students attending their provision. Their answers provide a view point on how they perceive the young people with

whom they work. Four key themes emerged from the seventeen responses. Eight heads noted issues with learning often framed in terms of previous experiences and resulting disaffection. Another eight mentioned challenging behaviour and seven discussed the impact of a home 
life mentioning trauma, instability and a lack of boundaries and support. A final five considered issues relating to confidence or self-esteem with two of these specifically mentioning a lack of trust. These findings show that heads of AP perceive the need for a far broader range of solutions and support than behaviour modification. It is interesting that issues related to learning are as highly prioritised as challenging behaviour. This suggests that for the young people with whom they work these heads perceive mainstream schooling to experience a comparable level of challenge with both difficult behaviour and meeting students learning needs.

Those conceptualising mainstream as ineffective for some pupils variously conceived the issues as pupils not fitting and thus being rejected from the mainstream setting, pupils presenting needs that schools don't have time or expertise to meet, pupils being failed by systems and targets which fail to recognise their potential, and mainstream schools as not always able to get the best out of their challenging pupils. For one head, greater flexibility was an important tool to address this issue:

I feel that mainstream schools do not always get the best out of their challenging pupils. In this provision we are able to be far more flexible in our teaching styles and approaches and this allows greater exploration in to how our pupils best learn (Head of Provision - survey)

That even the most challenging of pupils has untapped potential is the pivot that connects perceptions of mainstream schooling to their commitment to the young people with whom they work. 
When asked about what kept them working in alternative provision all respondents conceptualised their on-going motivation as the intrinsic rewards of the job and the impact they saw in the lives of the young people, a personal passion for the work or experiencing mastery of the skills required to work in AP. This would seem to suggest that although for some their commitment to the young people in their care is primarily underpinned by personal motivation, for the majority their motivation is more explicitly connected to the success they see in the lives of the young people with whom they work. For example two heads articulated their on-going motivation as:

The satisfaction of watching learners succeed and the journey they take as they develop and grow in a setting more appropriate to their quite specialised needs which are partly met be an alternate curriculum (Head of Provision - survey)

And

Seeing the positive changes young people make in their lives with the right support (Head of Provision - survey)

This builds on and strengthens the point made above; pupils who do not fit or who present challenges to the mainstream system still have potential, one head articulated:

passion for the unique individual that are too often failed by systems and targets that do not recognise their potential (Head of Provision - Survey)

In conceptualising the impact of their work some heads mentioned supporting young people through personal difficulties, indeed this can involve considerable success in the moment and significant learning for the young person. For the majority success was framed as accessing 
education and academic achievement that would enhance young peoples' opportunities in life.

Practical skills and experience together with an accredited qualification that will be useful to an employer (Head of Provision - survey)

And

I am passionate about helping young people to achieve academically as I believe education is the key to a better future (Head of Provision - survey)

An important element of this is engaging young people by making use of their present interests and future aspirations. Harnessing, in some cases establishing these can help young people as they progress beyond education. In one of the interviews a head of provision put this simply as 'I just want them to want something'. Other heads also responded in similar terms:

[We] help get the young people thinking about where they want to be and putting in place an action plan to help them achieve it (Head of Provision - survey)

And

We provide young people with an opportunity to get switched back on to learning, education and training, giving young people a chance to fulfil their true potential and become a valued member of society (Head of Provision - survey)

Perhaps the most novel and interesting finding to emerge from consideration of heads' motivations was the extent to which these were shaped by market dynamics. A total of seven heads responded in these terms. One formed their business so as to be able to exert greater 
control over ethos and two talked in terms of there being a need for the provision they offered. One head was approached by funders because of existing work in a related field and three others made explicit reference to a gap in the market. This related to either the ages catered for or the educational focus of the provision. Alternative provision exists as a market which is not as yet regulated in any standardised way (Ogg and Kaill, 2010 and Thomson and Pennacchia, 2014). Heads' accounts provide evidence of the power of market dynamics shaping provision. The importance of these findings will be considered in the discussion later.

\section{Areas of divergence in practice}

In addition to consideration of the areas of agreement which emerged it is also instructive to consider areas where practice or perception diverged in the responses received. The use of exclusion and restraint along with responses to negative relationships between staff and students were areas where this occurred.

Questions about the use of both restraint and exclusion elicited a similar spectrum of practice from these not being used at all to fairly common usage. Responses tended to correlate positively - those who didn't restrain didn't exclude and those who reported greater use of restraint also made more use of exclusion. For both practices around half of the respondents reported not using these at all or even that a counter policy was in place (de-escalation or non-exclusion). Of the other half most reported a low number of uses of these practices (5 or fewer uses of restraint, 1-2 exclusions) and a couple more significant use - two heads reported using restraint around 10 times in the last year. This diversity of practice was reflected in comments from one of the heads who was in a position to comment on practice in the area more generally: 
the culture of organisations does vary, in some restraint is quite common, it can be almost a daily event and in some in others its rare (Head of Provision - Interview)

In relation to exclusion a number of heads mentioned that students would move on to other providers. This could be due to the changing interests of the young person but was largely framed as progression or a positive response to pupils presenting difficulties in their current provision. Divergent practice in this area is likely to be connected to the organisational culture and as with other areas of significance the use of exclusion and restraint will be discussed later.

A mark of the culture found within alternative provision settings is the staff-student relationships which, as seen above, young people report as much more equal than those found in mainstream settings (Pomeroy, 1999; Lumby 2012). Reflecting this, when asked whether there was consensus in their staff group that a staff member should apologies in a situation where something they have done has negatively impacted on a student two heads were on the fence but the other 17 respondents agreed with 13 of these strongly agreeing. Although there was significant consensus about the kind of relational practice experienced by heads there was interesting divergence when respondents described how they would respond if a negative staff-student relationship emerged. Responses highlighted three key types of approach which could at times co-exist. The most common of these $(\mathrm{N}=8)$ was to engage the staff member and student together to work through the difficulties, possibly with some individual work beforehand. This is reflective of existing research which discusses the scale of AP as providing opportunities to deal with issues relationally (Thomson and Pennacchia, 2014) and of restorative models of practice. Indeed three heads made explicit mention of restorative 
practice - see Solomon and Thomas (2013) for the potential for restorative justice to be used in AP to the benefit of both staff and students. Interestingly, the second most common approach $(\mathrm{N}=5)$ was to suggest finding ways to disengage and diffuse the situation. This commonly involved changing groups (commonly moving the staff member or student if suitable) but also asking the staff member to take a break from the situation. This points in the direction of the last approach, reorienting the staff member to care. Four heads responded in these terms and suggested they would 'address the issue' with the member of staff and 'get the staff member to try to build a more positive relationship with the student'. This divergence between engagement and disengagement although not mutually exclusive, indeed one respondent mentions both, is interesting and will be considered below.

\section{Discussion}

This article has focused on the experiences of those who work in and manage alternative provision settings. The findings presented here offer a valuable contribution to the existing research on the experiences of staff in AP settings. While there are a number of studies which consider the experiences of staff in individual settings and in selected AP across the UK this research was undertaken across an English county. As such, where findings are in line with the existing research considerable weight can be given to their relevance to experiences within alternative provision more generally. Where findings diverge there is need for thoughtful reflection so as to consider the reasons for this. An example of this was the considerable differences in the thrust of the provision available. Compared to the findings of Thomson and Russell (2009) the provision available across the county in which this research took place was much more frequently of an academic focus. This either suggests variation by location or over time. Whilst there is clearer evidence for the former, the implications of the latter, that AP is becoming more academically focused, is concerning when considered in 
light of the work of Thomson and Pennacchia (2015) who suggest behavioural approaches may be on the rise in AP in England. This issue will be returned to below. This discussion will proceed by considering the implications of the key findings set out in this article. The developments to the idea of staff commitment will be considered first before working through the implications of the finding that market dynamics were one of the ways in which heads of provision had entered their role. Finally the areas of divergence in practice set out above will be considered in detail.

The accounts in this research offer a development of the ideas in the existing research which relate to staff commitment. Heads' accounts conceptualised the commitment of staff as belief in the young peoples' potential. This is similar to but arguably goes beyond staff conceptions of young people reported by Thomson and Pennacchia as 'essentially good and redeemable, with lives and paths that were not fixed' $(2014,25)$. Indeed, this notion of potential fits with the findings of Lumby that 'many young people were buoyed up by such a belief that they could achieve, that they were competent, just not in the way that was demanded for most of the time in school' $(2012,270)$. This finding, when combined with research undertaken by the author (Malcolm, 2015) which explored the longer term impact of the experience of attending AP, suggests that this commitment to students' potential can expand their horizons and give them a focus to move forwards positively. This only serves to once more confirm the need for systematic research into the longer term effects of alternative provision to back up the qualitative experiences reported elsewhere.

The extent to which market dynamics had been influential in the experience of those who had set up provisions was notable. There are research publications which consider market dynamics; Thomson and Russell (2009) discuss complex interactions between state policy 
and entrepreneurialism; Garner (1996) flags the limiting nature of funding being controlled by the local authority; and Thomson and Pennachhia (2014) explicitly mention the highly marketised nature of alternative provision in England as potentially driving down costs as providers compete for business. There would however seem to be significant potential to explore and develop understanding of how market dynamics shape the alternative provision on offer in any area. Research could usefully consider the complexities of seeking to shape this market positively whether by utilising buying power, specifying outcomes, offering incentives, developing localised reports on the available provision or any other available mechanisms. This is also particularly important given the policy changes set out at the beginning of this article. When and if the responsibility for commissioning provision for those permanently excluded is relocated to schools there will be far more fragmentation in the relationships which shape any local situation. Presently the local authority holds the responsibility for all pupils permanently excluded from mainstream. This means they will be a major commissioner within the local AP market and will therefore have the ability to influence the form and structure of provision available. Whether any LA is active in this ability is another question but the relocation of this responsibility to schools will bring significant change. If LAs lose their buying power but are still expected to shape the local market, as was set out in the White Paper, they will likely need other means by which to achieve this. Localised reporting on the quality and impact of provision would be one way to support this but given the fragmentation of the current schooling system this would likely require instigation from central government to be successful.

There were interesting divergences in practice with regards to the use of exclusion and restraint in the AP settings involved in this research. Given the broad skew towards the majority making no use of exclusion or restraint there would seem to be potential for non- 
exclusion and de-escalation policies to become the norm across AP settings. This would be in-line with and would support the relational approach advocated within the AP literature. These are practices which may well be amenable to influence via market dynamics as explored above and or improved localised reporting. In relation to exclusion more thought is required to explicitly define what is and is not acceptable with regards to the movement of young people around the alternative provision settings which are available to those with responsibility for placing them. The need for this is underscored by the lack of consistent record keeping across all AP and the way in which those involved tend to define movement from one provision to another as about finding a solution to difficulties. As these movements tend to be conceptualised as about what is best for the young person explicit use should be made of the concept of what is in the 'best interests' of the child as set out in the UNCRC (United Nations, 1989). At very least any move should be considered a positive step with agreement from both the young person and their parents or carers.

The last significant finding and another area where heads diverged in their accounts of how they practice was in responses to the emergence of a challenging relationship between a staff member and young person. Some would seek to diffuse the situation through separation whilst others would work to engage both staff member and student to work through the challenge. Engagement and disengagement are not necessarily on a spectrum, indeed one head suggested both the possibility of a joint discussion and of moving the student to another element of the provision if this was possible. Three heads made explicit mention of restorative approaches, others focused on reorienting staff members to care. There are similarities here with the work of Morgan et al. (2015) on developing 'reflective practitioners'. Given restorative approaches make relationships central to understanding complex situations there would seem to be potential for developing practice within AP 
settings by explicitly exploring restorative models and other approaches which ground practice in relationships.

This paper has considered the experiences of heads of alternative provision across an English county. Findings suggest provision can vary widely by area and, as a market, the form and structure of what is available is likely to be amenable to intervention. Given that responsibility for commissioning AP in England is likely to be relocated in future it is important to consider how these dynamics can best be influenced and who is in the best position to do this. For heads of provision findings showed a commitment to the potential of the young people with whom they worked and on-going motivation for their roles found in the successes they saw. It would appear to be these relational dynamics which underpin the effectiveness of alternative provision. There is however some cause for concern that this effectiveness may be undermined in the English context if Thomson and Pennacchia (2015) are correct in their assertion that behavioural approaches may be in the ascendancy. Further research could usefully consider whether there is indeed a rise in the use of behavioural approaches and the impact of this on the fundamentally relational nature of alternative provision. 


\section{References:}

Cajic-Seigneur, Magdalena, and Ann Hodgson. 2016. "Alternative educational provision in an area of deprivation in London." London Review of Education 14 (2):25-37. doi: 10.18546/LRE.14.2.03.

Cook, Lynne. 2005. "School without walls: reconnecting the disconnected at 14+." Support for Learning 20 (2):90-5. doi: 10.1111/j.0268-2141.2005.00367.x.

Cullen, Kairen, and Joyce Monroe. 2010. "Using positive relationships to engage the disengaged: An educational psychologist-initiated project involving professional sports input to a pupil referral unit." Educational and Child Psychology 27 (1):64-78.

Dean, Charlotte. 2016. "Seeking Educational Excellence Everywhere: an exploration into the impact of academisation on alternative education provision in England." FORUM: for promoting 3-19 comprehensive education 58 (3):355-63. doi: 10.15730/forum.2016.58.3.355.

DfE. 2014. "School exclusion trial evaluation." Available at:

https://www.gov.uk/government/uploads/system/uploads/attachment_data/file/331795/RR36

4 - School_Exclusion_Trial_Final_Report.pdf (Accessed: $9^{\text {th }}$ March 2016)

DfE. 2016a. "Registration of independent schools Departmental advice for proprietors and prospective proprietors of independent schools in England." Available at:

https://www.gov.uk/government/uploads/system/uploads/attachment data/file/492259/Regist ration_of_independent_schools.pdf (Accessed 22nd August 2016) 
DfE. 2016b. "Educational Excellence Everywhere." Available at:

https://www.gov.uk/government/uploads/system/uploads/attachment_data/file/508447/Educat ional Excellence Everywhere.pdf (Accessed: 22 ${ }^{\text {nd }}$ August 2016)

Dray, Susan. 2017. "Identity matters: Language, practices and the (non)performance of rudeness in a Pupil Referral Unit." Linguistics and Education 38:44-54. doi: 10.1016/j.linged.2017.02.001.

Farouk, Shaalan. 2014. "From Mainstream School to Pupil Referral Unit: A Change in Teachers' Self-Understanding." Teachers and Teaching: Theory and Practice 20 (1):19-31. doi: $10.1080 / 13540602.2013 .848518$

Farrell, Francis, Vicky Duckworth, Monika Reece, and Philip Rigby. 2017. "The moral frontiers of English education policy: governmentality and ethics within an alternative provision free school." Educational Review 69 (3):349. doi:

$10.1080 / 00131911.2016 .1223018$

Feltcher, John, Steve Strand, and Sally Thomas. 2015. "The Educational Progress of Looked After Children in England Technical Report 1: Secondary School Progress and Attainment." Rees Centre: University of Oxford. http://reescentre.education.ox.ac.uk/wordpress/wpcontent/uploads/2015/11/EducationalProgressLookedAfterChildrenTechnical-Report1_Nov2015.pdf. 
Garner, Philip. 1996. "A la Recherche du Temps Perdu: Case-study Evidence from Off-site and Pupil Referral Units." Children \& Society 10 (3):187-96. doi: 10.1111/j.10990860.1996.tb00468.x

Gov.uk. 2016. “The Queen's Speech 2016.” Available at: https://www.gov.uk/government/uploads/system/uploads/attachment_data/file/524040/Queen _s_Speech 2016 background notes_.pdf (Accessed: $23^{\text {rd }}$ August 2016)

Grundy, Wendy, and Sonia Blandford. 1999. "DEVELOPING A CULTURE FOR POSITIVE BEHAVIOUR MANAGEMENT." Emotional \& Behavioural Difficulties 4 (3):5-9. doi: 10.1080/1363275990040302

Kendall, S., Kinder, K., Halsey, K., Fletcher-Morgan, C., White, R. \& Brown, C. 2003. “An Evaluation of Alternative Education Initiatives.” National Foundation for Educational Research. Available at:

http://webarchive.nationalarchives.gov.uk/20130401151715/http://www.education.gov.uk/pu blications/eOrderingDownload/RR403.pdf (Accessed: $9^{\text {th }}$ March 2016)

Lumby, J. 2012. "Disengaged and disaffected young people: surviving the system.” British Educational Research Journal. 38 (2):261-279. Available at: http://onlinelibrary.wiley.com/doi/10.1080/01411926.2010.541553/abstract (Accessed: 9th March 2016) 
Malcolm, Andrew. 2015. "Alternative provision as an educational option: understanding the experiences of excluded young people." Professional Doctorate Thesis. University of Bedfordshire. Available at: http://hdl.handle.net/10547/608337 (Accessed: $13^{\text {th }}$ April 2017)

McCluskey, G., Lloyd, G., Riddell, S., Weedon, E., \& Fordyce, M. 2013. "Evaluation of education provision for children and young people educated outside the school setting." Welsh Government Social Research. Available at: http://www.docs.hss.ed.ac.uk/education/creid/Reports/31_WAG_EOTAS_FinalRpt.pdf (Accessed: $9^{\text {th }}$ March 2016)

McCluskey, Gillean, Sheila Riddell, and Elisabet Weedon. 2015. "Children's Rights, School Exclusion and Alternative Educational Provision." International Journal of Inclusive Education 19 (6):595-607. doi: 10.1080/13603116.2014.961677

Meo, Analia, and Andrew Parker. 2004. "Teachers, Teaching and Educational Exclusion:

Pupil Referral Units and Pedagogic Practice." International Journal of Inclusive Education 8 (1):103-20. doi: 10.1080/1360311032000159465

Nicholson, Laura J., and Dave W. Putwain. 2015. "Facilitating re-engagement in learning: A disengaged student perspective." Psychology of Education Review 39 (2):37-41.

Ofsted. 2011. “Alternative provision." Available at: https://www.gov.uk/government/uploads/system/uploads/attachment data/file/413554/Altern ative provision.pdf (Accessed: $9^{\text {th }}$ March 2016) 
Ofsted. 2016a. “Advice letter from Sir Michael Wilshaw, Her Majesty’s Chief Inspector, to the Secretary of State for Education on unregistered schools.” Available at:

https://www.gov.uk/government/uploads/system/uploads/attachment_data/file/523694/Unregi stered_schools_advice_note_16_May_2016.pdf (Accessed 22nd August 2016)

Ofsted. 2016b. "Alternative provision: The findings from Ofsted's three-year survey of schools' use of off-site alternative provision.” Available at:

https://www.gov.uk/government/uploads/system/uploads/attachment_data/file/500918/Altern ative provision findings from Ofsteds threeyear_survey of schools use of offsite alternative provision.pdf (Accessed: $1^{\text {st }}$ September 2017)

Ogg, Tom, and Emily Kaill. 2010. “A New Secret Garden? Alternative Provision, Exclusion and Children's Rights.” Civitas. Available at:

http://www.civitas.org.uk/pdf/NewSecretGarden.pdf (Accessed 1st September 2017)

O'Gorman, Eva, Nancy Salmon and Carol-Anne Murphy. 2016. "Schools as sanctuaries: A systematic review of contextual factors which contribute to student retention in alternative education." International Journal of Inclusive Education 20(5): 536-551. doi: $10.1080 / 13603116.2015 .1095251$

Pirrie, Anne, Gale Macleod, Mairi Ann Cullen, and Gillean McCluskey. 2011. "What happens to pupils permanently excluded from special schools and pupil referral units in England?" British Educational Research Journal 37 (3):519-38. doi:

$10.1080 / 01411926.2010 .481724$. 
Pomeroy, Eva Nicole. 1999. "The Teacher-Student Relationship in Secondary School: Insights from excluded students." British Journal of Sociology of Education 20(4):465-82. doi: $10.1080 / 01425699995218$

Solomon, Mike, and Gaby Thomas. 2013. "Supporting behaviour support: developing a model for leading and managing a unit for teenagers excluded from mainstream school." Emotional \& Behavioural Difficulties 18 (1):44-59. doi: 10.1080/13632752.2012.689566.

Taylor, Charlie. 2012. "Improving Alternative Provision.” Available at:

https://www.gov.uk/government/uploads/system/uploads/attachment data/file/180581/DFE00035-2012.pdf (Accessed: $9^{\text {th }}$ March 2016)

Thomson, Pat. 2014. "What's the alternative? Effective support for young people disengaging from the mainstream." The Prince's Trust. Available at:

https://alternativeducationresearch.files.wordpress.com/2014/10/literature-review-final-1510-14.pdf (Accessed 20 ${ }^{\text {th }}$ April 2018)

Thomson, Pat, and Jodie Pennacchia. 2014. "What's the alternative? Effective support for young people disengaging from mainstream education.” The Prince's Trust. Available at: https://alternativeducationresearch.files.wordpress.com/2014/10/education-report-final-14thoctober-2014.pdf (Accessed 1st September 2017)

Thomson, Pat. and Jodie Pennacchia. 2016. "Hugs and behaviour points: Alternative education and the regulation of 'excluded' youth." International Journal of Inclusive Education 20(6): 622-40. doi: 10.1080/13603116.2015.1102340 
Thomson, Pat, and Lisa Russell. 2009. "Data, data everywhere - but not all the numbers that count? Mapping alternative provisions for students excluded from school.” International Journal of Inclusive Education. 13 (4): 423-38. Available at:

http://www.tandfonline.com/doi/abs/10.1080/13603110801983264\#.VuAw-UBK23g (Accessed: $9^{\text {th }}$ March 2016)

Trotman, Dave, Stanley Tucker, and Madeline Martyn. 2015. "Understanding problematic pupil behaviour: perceptions of pupils and behaviour coordinators on secondary school exclusion in an English city." Educational Research 57 (3):237-53. doi: 10.1080/00131881.2015.1056643.

United Nations. 1989. "United Nations Convention on the Rights of the Child (UNCRC)". Geneva: United Nations.

Willis, Gordon B. 1999. “Cognitive Interviewing - A ‘how to’ guide.” Short course presented at the 1999 meeting of the American Statistical Association. Available at: http://appliedresearch.cancer.gov/archive/cognitive/interview.pdf (Accessed: 9th March 2016)

Woodley, Helen. 2016. "THE USE OF AUTO-ETHNOGRAPHY IN CLASSROOM BASED PRACTITIONER RESEARCH." Annual Review of Education, Communication \& Language Sciences 13:44-56. Available at: https://research.ncl.ac.uk/ARECLS/volume 13/Helen\%20Woodley.pdf (Accessed: $1^{\text {st }}$ September 2017) 
